\title{
SIR/RSNA/CIRSE Joint Medical Simulation Task Force Strategic Plan: Executive Summary
}

\author{
Derek Gould • Aalpen Patel • Gary Becker • Buddy Connors • \\ John Cardella $\cdot$ Steven Dawson · Craig Glaiberman - David Kessel · \\ Mick Lee - William Lewandowski - Roger Phillips · Jim Reekers · \\ David Sacks $\cdot$ Marc Sapoval $\cdot$ Mark Scerbo
}

Published online: 23 July 2009

(C) Springer Science+Business Media, LLC and the Cardiovascular and Interventional Radiological Society of Europe (CIRSE) 2009

\section{Erratum to: Cardiovasc Intervent Radiol}

(2007) 30:551-554

DOI 10.1007/s00270-007-9103-9

In the online and print versions of this article, Springer

Science+Business Media, LLC was cited incorrectly as the

The online version of the original article can be found under doi:10.1007/s00270-007-9103-9.

D. Gould ( $ه$ )

Radiology Department, Royal Liverpool University Trust,

Liverpool, UK

e-mail: dgould@liv.ac.uk

A. Patel

Department of Radiology, University of Pennsylvania

School of Medicine, Philadelphia, PA 19104, USA

G. Becker

Department of Radiology, University of Arizona

College of Medicine, Tucson, AZ, USA

B. Connors

Radiology Associates of Sacramento, Sacramento, CA, USA

J. Cardella

Department of Radiology, Baystate Health System/Tufts

University School of Medicine, 759 Chestnut Street,

C3162, Springfield, MA 01199, USA

\section{S. Dawson}

Department of Radiology, Massachusetts General Hospital,

Harvard Medical School, Boston, MA, USA

C. Glaiberman

Mallinckrodt Institute of Radiology, Washington University

School of Medicine, 510 South Kingshighway Boulevard,

Box 8131, St. Louis, MO 63110, USA copyright holder, when in fact the actual copyright holder of this article is the Society of Interventional Radiology (SIR).

D. Kessel

Leeds Teaching Hospitals, Leeds, UK

M. Lee

Department of Radiology, Beaumont Hospital,

Royal College of Surgeons in Ireland, Dublin, Ireland

W. Lewandowski

William E. Lewandowski Consulting, Daytona Beach, FL, USA

R. Phillips

Department of Computer Science, University of Hull,

Hull, UK

J. Reekers

Department of Radiology, Academic Medical Centre,

Amsterdam, The Netherlands

D. Sacks

Department of Radiology, The Reading Hospital and Medical

Center, Reading, PA, USA

M. Sapoval

Department of Radiology, Hopital Europeen G, Pompidou, Paris, France

M. Scerbo

Department of Psychology, Old Dominion University,

Norfolk, VA, USA 